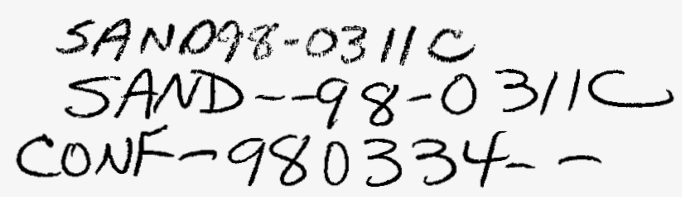

\title{
Ultrasonic inspection technique for composite doubler/aluminum skin bond integrity for aircraft
}

\author{
John H. Gieske, Dennis P. Roach, and Phillip D. Walkington \\ Sandia National Laboratories, MS0615, Albuquerque, NM 87185
}

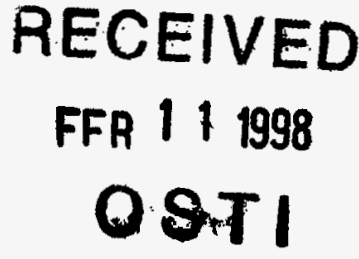

As part of the FAA's National Aging Aircraft Research Program to foster new technologies for civil aircraft maintenance and repair, use of bonded composite doublers on metal aircraft structures has been advanced. Research and validation of such doubler applications on U.S. certified commercial aircraft has begun. A specific composite application to assess the capabilities of composite doublers was chosen on a L-1011 aircraft for reinforcement of the corner of a cargo door frame where a boron-epoxy repair patch of up to 72 plies was installed. A primary inspection requirement for these doublers is the identification of disbonds between the composite laminate and the aluminum parent material. This paper describes the development of an ultrasonic pulse-echo technique using a modified immersion focus transducer where a robust signal amplitude signature of the composite/aluminum interface is obtained to characterize the condition of the bond. Example waveforms and $\mathrm{C}$-scan images are shown to illustrate the ultrasonic response for various transducer configurations using a boron-epoxy/aluminum skin calibration test sample where disbonds and delaminations were built-in. The modified focus transducer is compatible with portable ultrasonic scanning systems that utilize the weeper or dripless bubbler technologies when an ultrasonic inspection of the boron-epoxy composite doublers installed on aircraft is implemented.

Keywords: ultrasonic inspection, nondestructive inspection, boron-epoxy composite, aircraft doubler, disbond detection, bond integrity, aging aircraft, aircraft repairs

\section{INTRODUCTION}

The Airworthiness Assurance NDI Validation Center (AANC) was established at Sandia National Laboratories to support nondestructive inspection (NDI) technology development and assessment for aircraft. The AANC is funded by the Federal Aviation Administration (FAA) William J. Hughes Technical Center, Atlantic City, NJ. The FAA's National Aging Aircraft Research Program supports development of new technologies for civil aircraft maintenance and repair. A recent advance has been the research and validation of bonded composite doublers applied on U.S. certified commercial aircraft structures for the repair of cracks and corrosion in the aluminum skin of aging aircraft. The composite doubler repair has several advantages over conventional repairs now being done which include: corrosion resistance; light weight/high strength; elimination of rivets and additional rivet holes in the skin; conforms easily to complex shapes; only access to the outside of the fuselage is needed; and, the technology has the potential for substantial cost and time savings.

A study to assess the performance capabilities of composite doublers was chosen on a L-1011 aircraft for reinforcement of the upper right corner of a cargo door frame of the fuselage. For this application, a boron-epoxy repair patch of 72 plies was installed. The AANC is conducting a technology evaluation of this application with support from Delta Air Lines, Lockheed Martin, Textron, and the FAA. Through the use of laboratory test structures and a fuselage section cut from a retired L-1011 aircraft, an evaluation of the boron-epoxy composite design, fabrication, installation, structural integrity, and nondestructive inspection is being conducted.

Acceptance of composite doublers by civil aviation industry depends highly on a quick and comprehensive assessment of the integrity of the doubler at the initial installation of the composite doubler and at regular inspection intervals of the aircraft. In particular, identification of disbonds between the doubler and the aluminum skin and delaminations within the composite are important since these defects prevent the doubler to perform as designed ${ }^{1,2,3}$. To meet the inspection requirements, this paper describes the development of an ultrasonic inspection technique using a modified focus transducer to identify disbonds between the composite doubler and the aluminum skin of the fuselage. Disbonds can occur at installation of the doubler or at anytime during the service life of the aircraft. Conventional pulse-echo techniques using
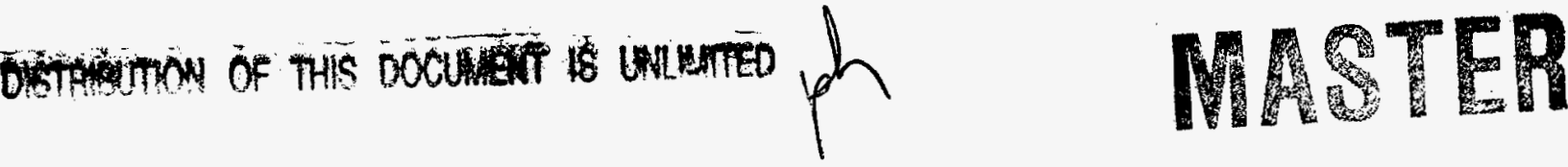
flat or normal focus transducers were not effective in characterizing the disbond condition of the composite/aluminum interface.

\section{BORON-EPOXY DOUBLER DESIGN}

The elements of the boron-epoxy composite doubler are shown in Figure 1 where the thickness dimensions are greatly exaggerated to illustrate the lay-up construction of the composite. The aluminum skins where the doublers are normally installed range in thickness from 0.04 to 0.07 inch. A typical application of a composite doubler or repair patch is shown in Figure 1 for the case of a fatigue crack repair.

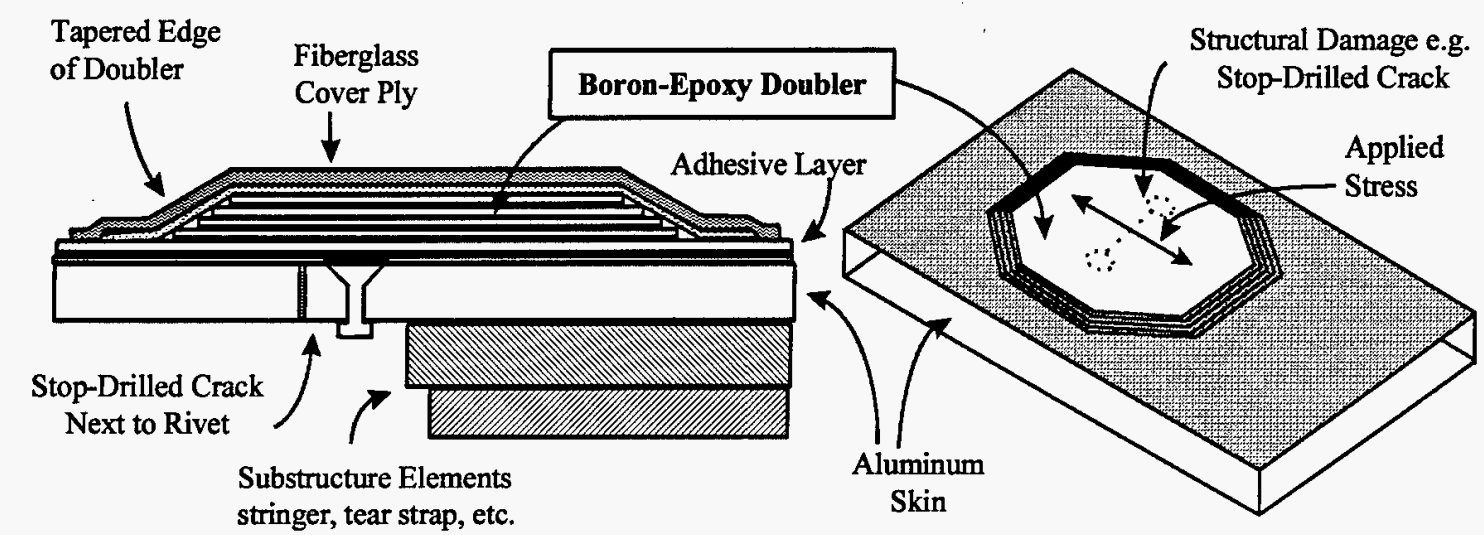

Figure 1. Construction elements of a boron-epoxy composite doubler on an aircraft aluminum skin.

The number of plies and fiber orientation of the composite is determined by the nature of the reinforcement required. For the application of the doubler at the L-1011 cargo door frame, a boron-epoxy composite of 72 plies was required where alternate ply orientations of 0,90 , and $+/-45$ degrees were used. The tapered region near the perimeter of the doubler as shown in Figure 1 is necessary to achieve a uniform stress field in the area of maximum load transition. Inspection for

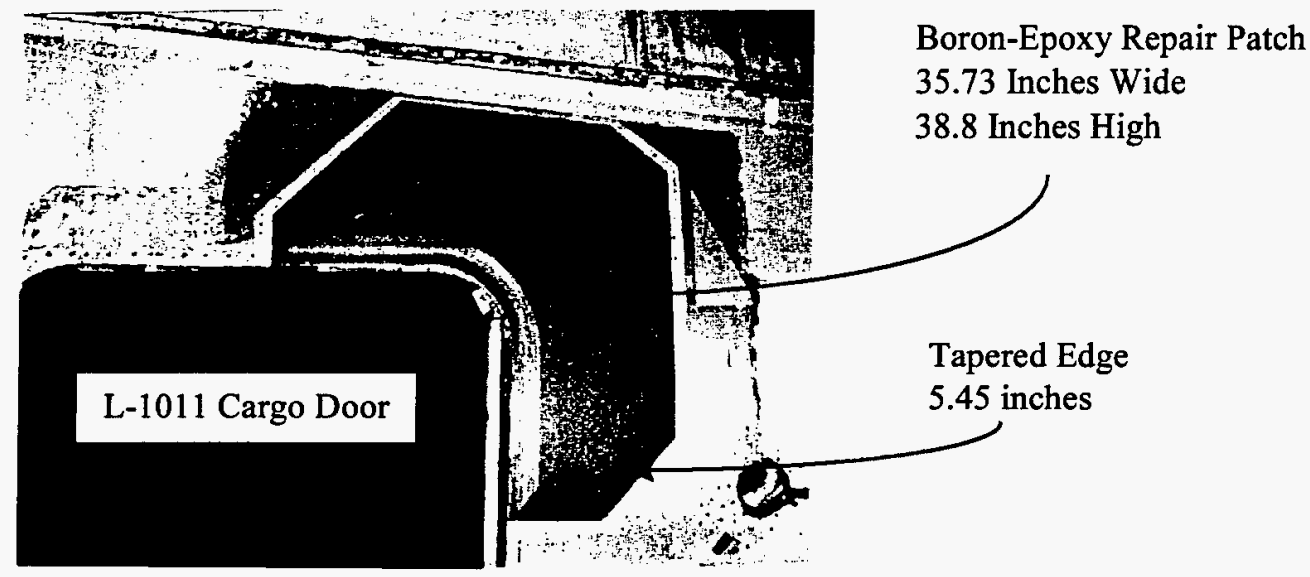

Figure 2. The boron-epoxy reinforcement repair doubler applied to the upper right section of the L-1011 cargo door frame.

doubler disbonds is particularly important in the tapered region of the repair patch. The over all dimensions of the L-1011 repair patch are shown in Figure 2 where the boron-epoxy composite doubler has been installed on the laboratory test sample of a L-1011 fuselage section that was cut from a retired aircraft. 


\section{DISCLAIMER}

This report was prepared as an account of work sponsored by an agency of the United States Government. Neither the United States Government nor any agency thereof, nor any of their employees, makes any wartanty, express or implied, or assumes any legal liability or responsibility for the accuracy, completeness, or usefulness of any information, apparatus, product, or process disclosed, or represents that its use would not infringe privately owned rights. Reference herein to any specific commercial product, process, or service by trade name, trademark, manufacturer, or otherwise does not necessarily constitute or imply its endorsement, recommendation, or favoring by the United States Government or any agency thereof. The views and opinions of authors expressed herein do not necessarily state or reflect those of the United States Government or any agency thereof. 


\section{ULTRASONIC CALIBRATION TEST SAMPLE}

A boron-epoxy calibration test sample was constructed with built-in flaws representing delaminations within the plies of the composite and disbonds at the aluminum skin. Thin Teflon shims were used to simulate the flaws within the composite structure. Pull tabs were used at the edges of the composite which were removed after cure of the epoxy to simulate the flaws in those regions. Five 4-inch wide strips of the composite with lay-ups from 8 to 72 plies were installed on a 0.07 inch thick aluminum panel to make up the entire calibration test sample that is illustrated in Figure 3.

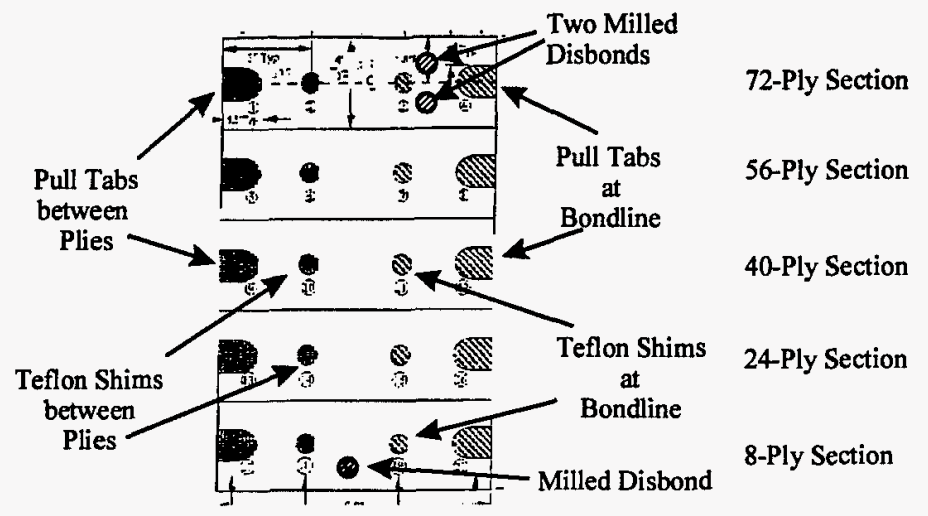

Figure 3. Ultrasonic calibration test sample simulating delaminations and disbonds for boron-epoxy doublers ranging from 8 to 72 plies.

\section{ULTRASONIC TECHNIQUES}

To characterize the built-in flaws and assess the overall uniformity of the composite strips of the calibration sample, a through transmission C-scan image of the signal amplitude for each strip of the test sample was recorded using a pair of 5 $\mathrm{MHz}, 1 / 2$ inch diameter transducers. The C-scan images for the 72-ply section and the 8-ply section are shown in Figure 4. The $\mathrm{C}$-scan images are normally produced in 16 color contours but for this publication the images were converted to a gray
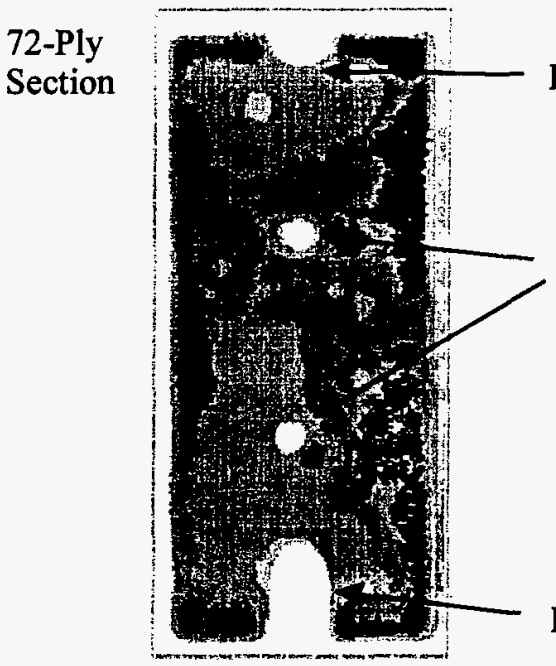
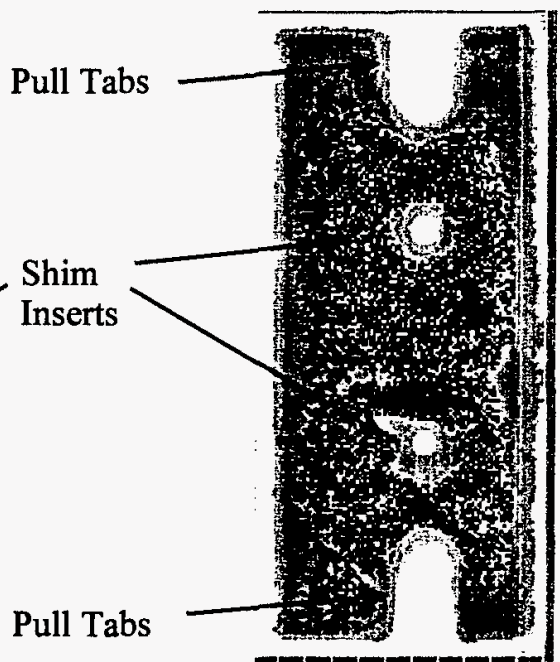

8-Ply

Section

Black Areas - High Amplitude Signals

Gray Areas - Lower Amplitude Signals

White Areas - No Signal Recorded Indicating Air Interface

Figure 4. Through transmission C-scan images of the 72-ply and 8-ply sections of the ultrasonic calibration test sample.

scale with less resolution between contours so that distinguishing features within the images are clearly visible in the half tone black and white print format. In Figure 4, the pull tab region at the top of the 72-ply section shows an incomplete 
delamination in the intended area. Non-uniform areas of the composite are also evident by the reduction of the signal amplitude recorded in regions of the normal composite lay-up. The $\mathrm{C}$-scan image of the 8-ply section indicates a faithful representation of the intended flaws and no non-uniform areas are observed in the remainder of the composite lay-up. The through transmission C-scan images are helpful when interpreting the response waveforms using a pulse-echo technique in the same respective areas of the composite. For example, air interfaces at the intended flaw areas are confirmed by the through transmission data and the maximum change in the pulse-echo amplitude is expected at the same areas.

Furthermore, other areas of the composite are identified where the pulse-echo amplitude from the composite/aluminum interface may vary due to the non-uniformity of the "normal" lay-up of the composite by as much as the pulse-echo amplitude would change due to a disbond. The incomplete delamination area in the region of the pull tab in the 72-ply section as recorded by the through transmission $\mathrm{C}$-scan can help explain the possible pulse-echo amplitude variations that will be recorded in this region.

Preliminary pulse-echo data for the calibration test sample were recorded using a $5 \mathrm{MHz}, 1 / 2$ inch diameter, 2 inch focus transducer. Pulse-echo waveforms were recorded over the built-in flaws that were indicated by the through transmission data of Figure 4 to have air interfaces present at the intended areas. Figure 5 shows the pulse-echo response waveforms recorded while passing the transducer over the corresponding disbond and delamination areas within the center portion of

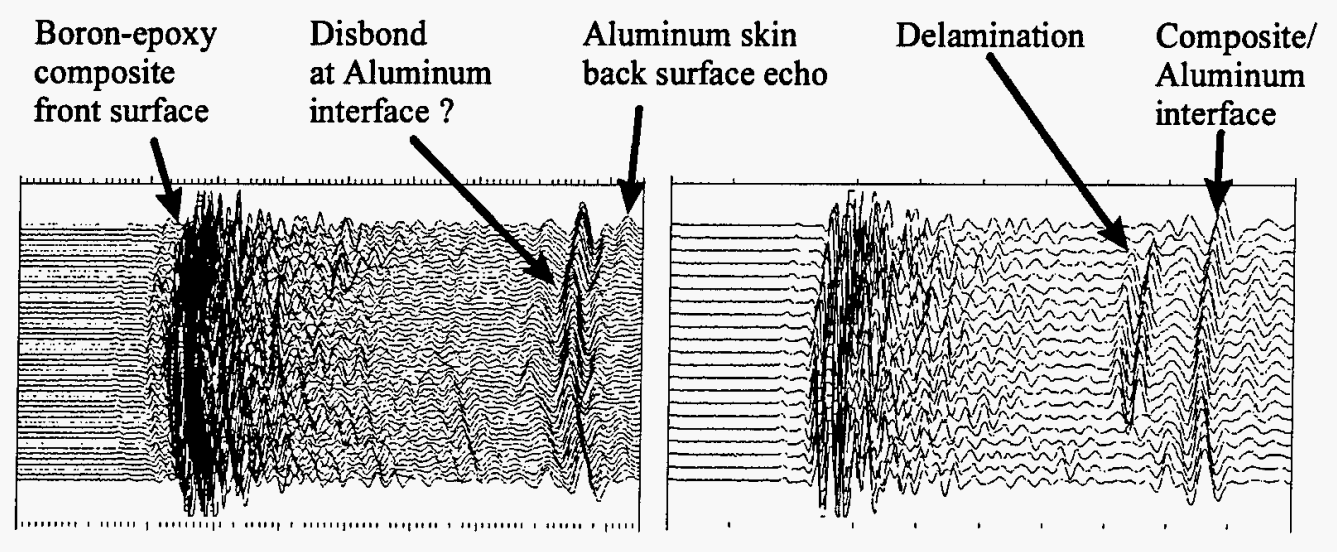

Figure 5. Waterfall plots of the pulse-echo waveform while passing over the area of the disbond and the delamination within the body of the 72-ply section of the calibration test sample.

the 72-ply section of the test sample. As seen in Figure 5, the pulse-echo response for the "delamination" is clearly seen in the waveforms but the pulse-echo response for the "disbond" is not distinct. No phase reversal or increase in signal amplitude for the bond-line echo is displayed at the disbond. A slight indication of the presence of the Teflon shim is evident by the small shift of the bond-line echo to a shorter Time-Of-Flight (TOF) indicating a thinner adhesive thickness layer at the shim.

Since the presence of the Teflon shim could mask the true nature of a disbond at the aluminum interface, two additional disbond areas were fabricated in the 72-ply section near the Teflon shim area. These two areas are identified in Figure 3. The two new "disbonds" were created by carefully milling the aluminum base metal until very small areas of the adhesive interface were exposed. The remaining aluminum film was pulled away from the adhesive and area was then covered with a watertight adhesive tape so that an air interface was present at the bond-line of the adhesive/aluminum interface. A similar area was also fabricated in the 8-ply section as identified in Figure 3.

C-scan images of the 72-ply section for a range gate set for the pulse-echo waveform at the bond-line echo are shown in Figure 6 for scans performed before and after milling of the additional "disbond" areas. For comparison, in order to show the effect of the milling process, $\mathrm{C}$-scan images are also shown in Figure 6 where the range gate was set at the back surface echo of the aluminum plate. The back surface echo of the aluminum plate is present for the plain aluminum plate used for the calibration test sample but for applications of the composite on an aircraft, the aluminum back surface echo will not in general be available. For aircraft, the aluminum skin can be multi-layered, backed by lap joints, stringers, tear straps etc., 


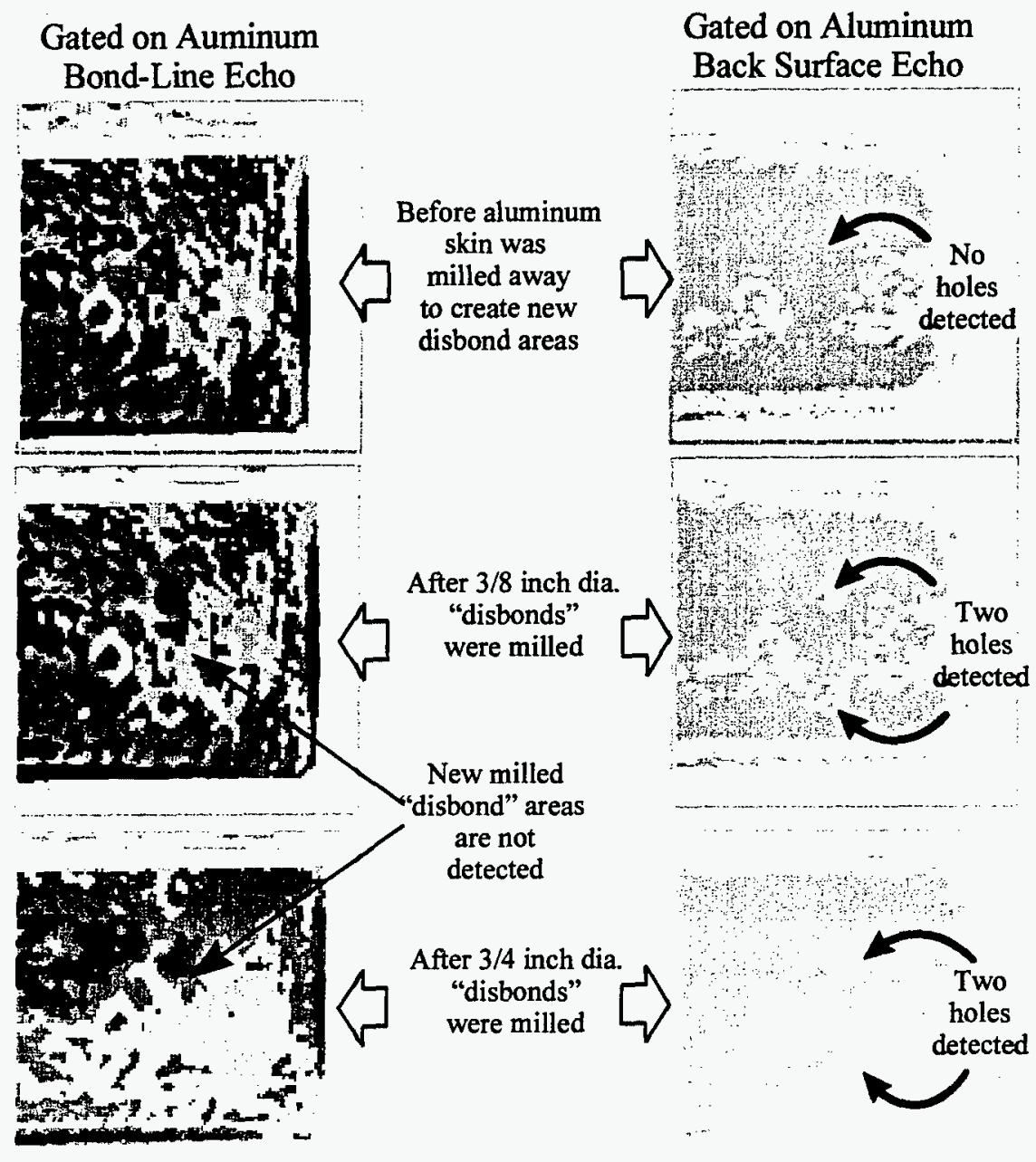

Figure 6. C-scan images for the 72-ply section of the calibration test sample with the range gate set at the aluminum bondline echo and at the aluminum back surface echo before and after new "disbonds" were created.

or it may be coated on the inside with an anti-corrosion paint layer. Any one of these conditions can interfere with the aluminum thickness echo response. For this reason, no characterization of the disbond area using the aluminum back surface echo will be attempted here other than the comparison made in Figure 6 to show the exact extent and location of the milled area in the C-scan image.

\section{TRANSDUCER MODIFICATIONS}

From the C-scan images of composite/aluminum bond-line echo amplitudes in Figure 6, it is observed that the presence of a disbond at the aluminum bond-line interface is not detectable with the conventional pulse-echo technique. No significant echo amplitude change is observed at the disbond to be greater than that due to the normal lay-up of the composite using the $1 / 2$ inch diameter focus transducer. However, a noticeable change in the bond-line echo response at the disbond was observed by using a $5 \mathrm{MHz}, 1.0$ inch diameter, 2 inch focus transducer. The change in the echo response for the 1.0 inch diameter transducer was also greatly enhanced by placing a $3 / 8$ inch diameter stop in the center of the transducer.

A diagram is shown in Figure 7 where ray traces are drawn from the 1.0 inch diameter transducer for focusing on the aluminum bond-line interface of the 72-ply boron-epoxy repair patch. The large refracted angles for the outer rays of the ultrasonic beam are due to the elastic anisotropy of the composite that changes significantly from the thickness direction to the transverse direction of the composite. The refracted angles in the composite shown in Figure 7 were calculated using L- 


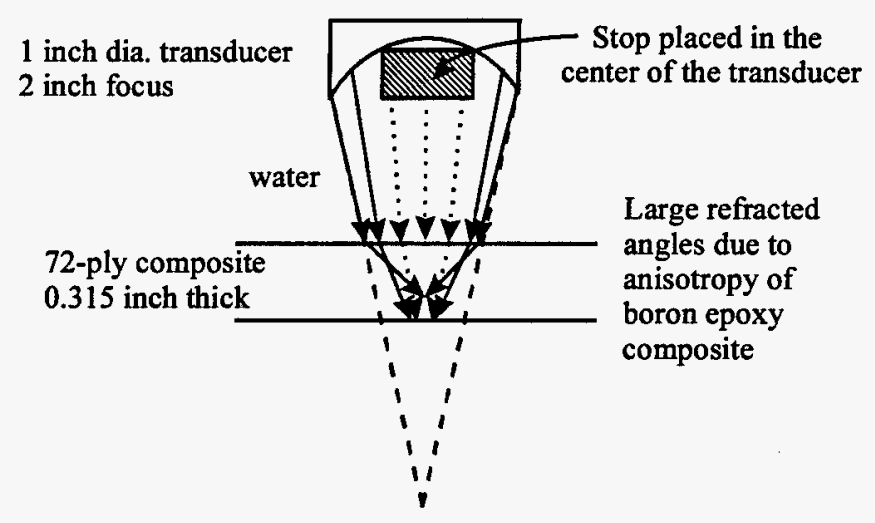

Figure 7. Ray traces for a 1.0 inch diameter, 2 inch focus transducer and a 72-ply boron-epoxy sample.

wave velocity values that were determined in a small 72-ply boron-epoxy coupon. The L-wave velocities for different angular orientations in the coupon are listed in Table $\mathrm{I}$.

Table I. Lwave velocity values measured in the boron-epoxy composite

\begin{tabular}{c|c}
$\begin{array}{c}\text { Wave Propagation } \\
\text { Direction }\end{array}$ & $\begin{array}{c}\text { L-wave Velocity } \\
(\mathbf{m m} / \mathbf{\mu s})\end{array}$ \\
\hline Thickness $0^{\circ}$ & 3.48 \\
$5^{\circ}$ & 3.43 \\
$10^{\circ}$ & 3.43 \\
$12.5^{\circ}$ & 3.51 \\
$14^{\circ}$ & 3.78 \\
$15^{\circ}$ & 4.14 \\
Transverse $90^{\circ}$ & 6.73
\end{tabular}

From Figure 7, it is seen that placing a stop ( $3 / 8$ inch diameter and $1 / 4$ inch thick cork button) in the center of the transducer, the zero degree ray together with all low angle rays are blocked so that only the faster velocity rays are transmitted in the sample at large refracted angles. The faster velocity rays interact with the bond-line interface in a way to enhance the difference of the echo response between bonded and non-bonded conditions of the interface.

\section{FINAL RESULTS}

The C-scan images for the 72-ply and the 8-ply sections of the calibration test sample are shown in Figure 8 where the range gate was set on the positive half cycle amplitudes of the bond-line echo using the modified 1.0 inch diameter, 2 inch focus transducer. Also shown in Figure 8 are waveforms recorded at the locations of the disbond and at a "normal" bonded area. The echo response using the modified focus transducer clearly displays an apparent phase reversal and an apparent increase of the positive half cycles of the echo. By setting a TOF gate for only negative cycles of the echoes, a robust and unambiguous $\mathrm{C}$-scan image of the disbonded areas in the boron-epoxy/aluminum interface are produced as illustrated in Figure 9. The disbond area at the Teflon shim is also displayed in Figure 9; but, as mentioned above, it was not clear whether the shim thickness itself is totally or in part responsible for the detection of the intended disbonded area.

The results presented in this paper were recorded by an ultrasonic data acquisition system with the samples placed in a water immersion tank. The modified focus transducer described here can be used with a portable ultrasonic data acquisition and display system. For the portable system, the immersion focus transducer is placed into the body of the weeper $^{4}$ or dripless bubbler ${ }^{5}$ transducer holder. These bodies contain a captured water column held in place by a thin membrane at the front end of the transducer holder. The weeper or dripless bubbler transducer bodies normally use $1 / 2$ inch diameter transducers. For the weeper transducer holder, the water cavity was machined into a conical shape to accommodate the 1.0 inch diameter transducer without any problems. A picture of the weeper transducer arrangement attached to a portable 


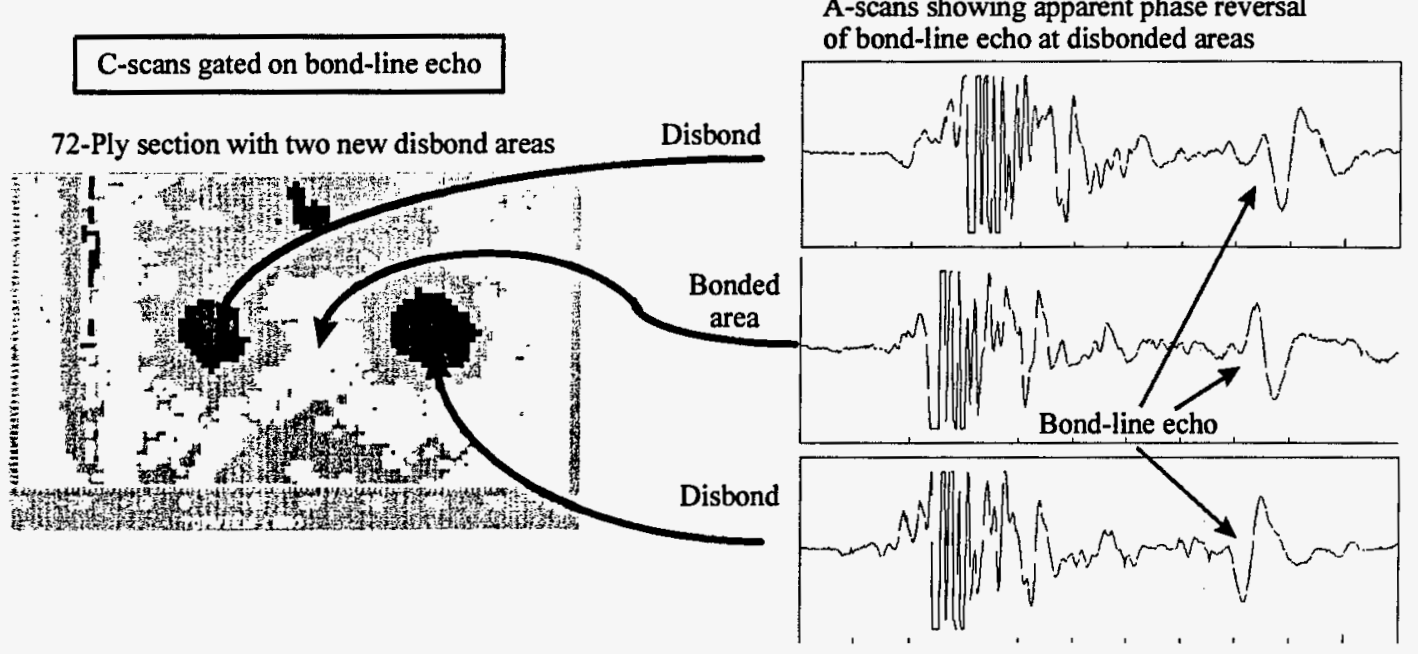

8-Ply section with one new disbond area

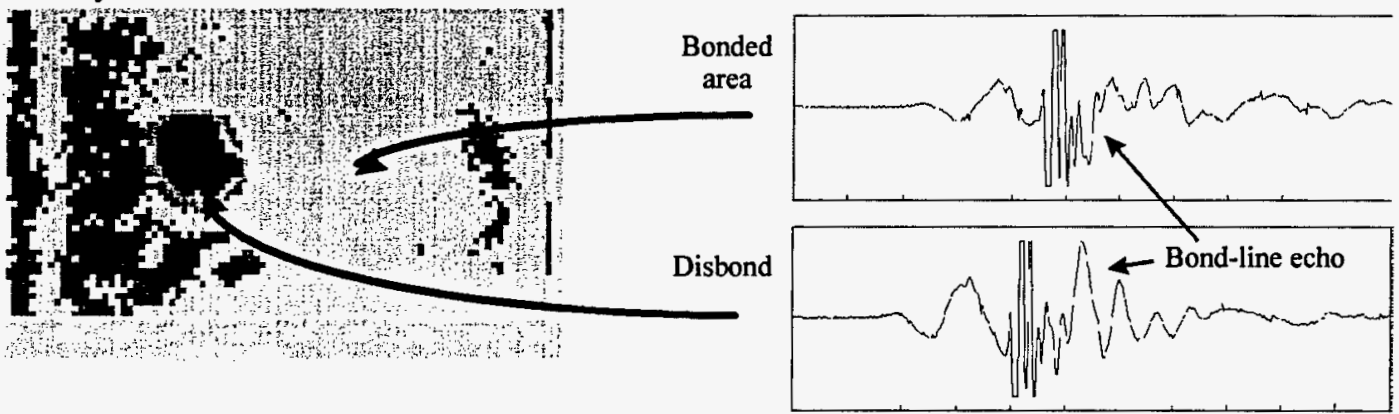

Figure 8. C-scans and waveforms recorded at the new "disbond" areas of the calibration test sample.

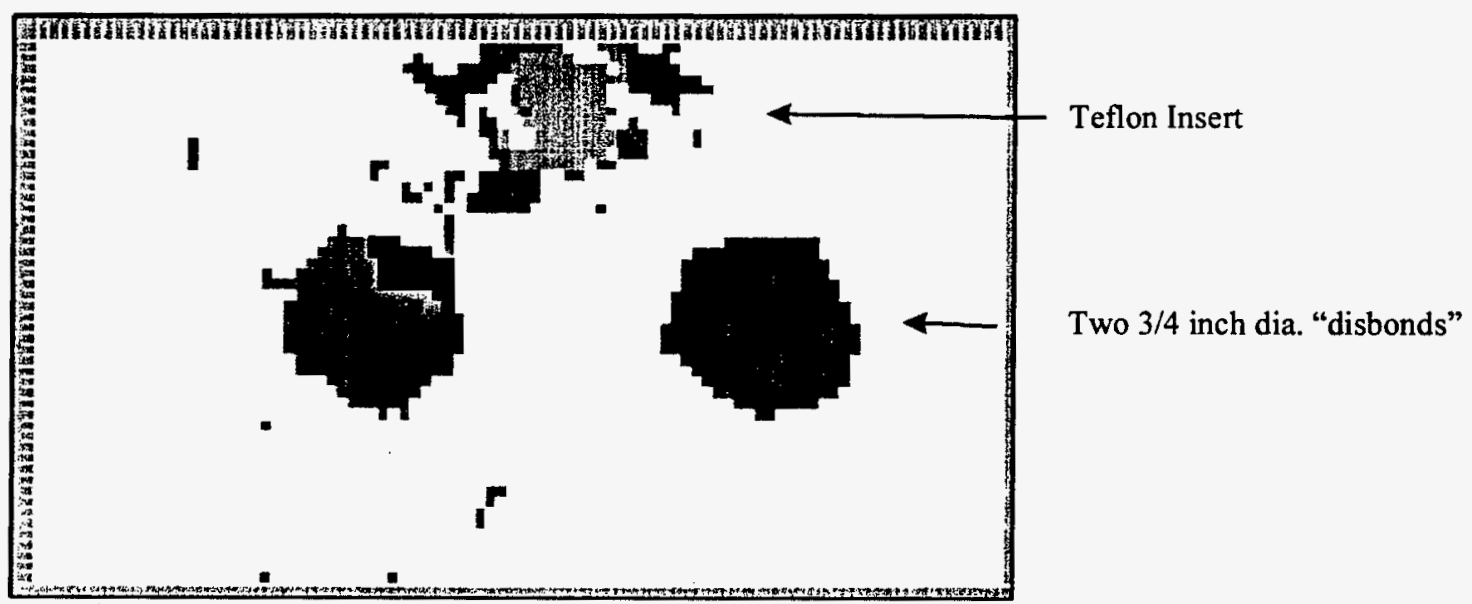

Figure 9. Time-OF-Flight (TOF) plot of the new "disbonds" in the 72-ply section of the calibration test sample. 


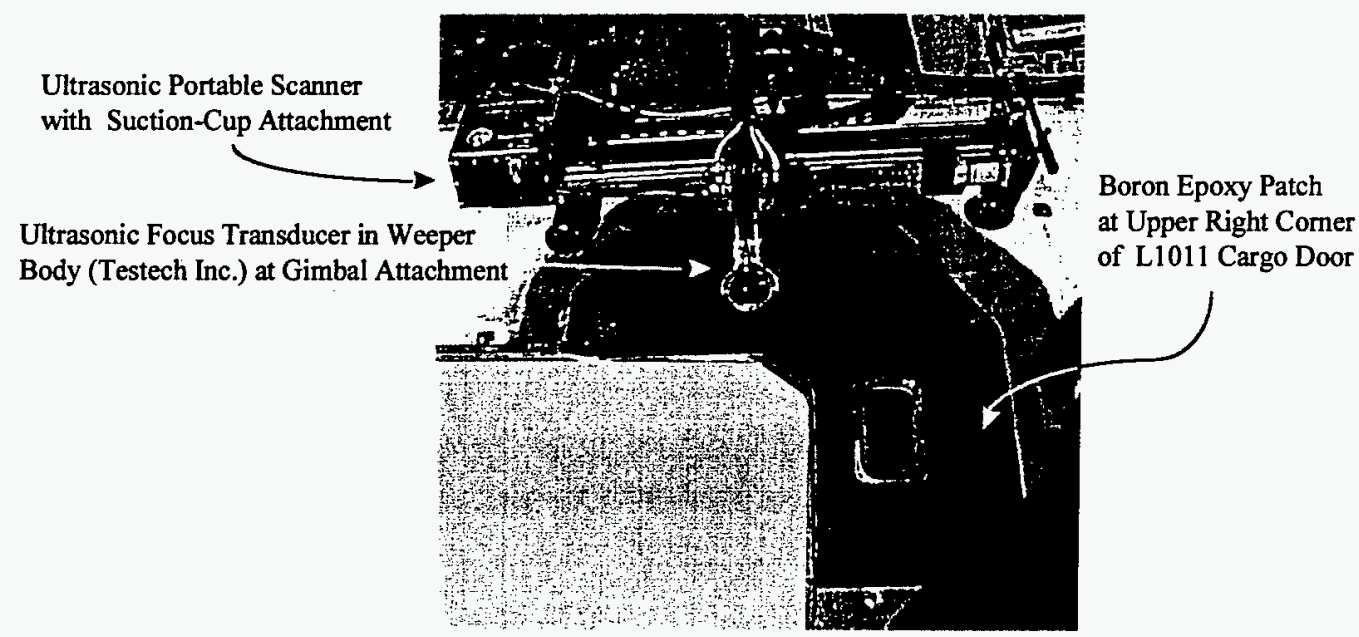

Figure 10. The weeper transducer holder attached to a portable ultrasonic scanner for implementation of the ultrasonic inspection for the L-1011 repair patch.

ultrasonic scanner for implementation of an automated ultrasonic inspection of the L-1011 boron-epoxy doubler is shown in Figure 10.

\section{CONCLUSIONS}

A pulse-echo technique was developed that produces a significant change in the pulse-echo response from a boronepoxy/aluminum skin interface where disbonds are present. As a result, ultrasonic inspections of boron-epoxy doublers can be conducted where Time-OF-Flight C-scan images can be produced that show unambiguously the disbonded areas at the aluminum skin interface.

The technique is compatible with portable ultrasonic scanning systems that utilize weeper or dripless bubbler technologies.

\section{ACKNOWLEDGEMENTS}

This work was supported by the William J. Hughes Technical Center under Sandia National Laboratories contract number DTFA-03-91-A-0018.

\section{REFERENCES}

1. T.P Lynch, "Composite patches reinforce aircraft structures", Design News, April 1991.

2. D. R. Roach, "Performance analysis of bonded composite doublers on aircraft structures", $10^{\text {th }}$ International Conference on Composite Materials, August 1995.

3. E. B. Belason, P. Rutherford, M. Miller, and S. Raj, "Evaluation of bonded boron/epoxy doublers for commercial aircraft aluminum structures", FAA/NASA Int. Symposium on Aircraft Structural Integrity, May 1994.

4. TESTTECH, Inc. 115 Summit Drive, PO Box 960, Exton, PA 19341.

5. SIERRA MATRIX Inc., 48890 Milmont Drive, Ste 105D, Fremont, CA 94538. 


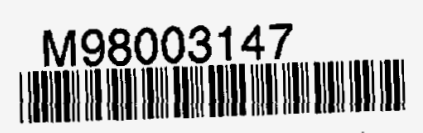

Report Number (14) $\frac{\delta A N D--98-0311 C}{\text { CONF-980334- }}$

Subl. Date (11) 199802

Sponsor Code (18) DUs , XF

JC Category (19) UC- OO, DOE/ER 